\title{
Treatment of nongonococcal urethritis with rifampicin as a means of defining the role of Ureaplasma urealyticum
}

\author{
E. D. COUFALIK, ${ }^{*}$ D. TAYLOR-ROBINSON,* AND G. W. CSONKA† \\ From the *Division of Communicable Diseases, MRC Clinical Research Centre, Harrow, Middlesex, and \\ the Central Middlesex Hospital, London
}

SUMMARY The results of a double-blind therapeutic trial on 217 men with nongonococcal urethritis (NGU) show that minocycline was more effective than rifampicin. Before treatment Chlamydia trachomatis was isolated from $43 \%$ of men, Ureaplasma urealyticum from $59 \%$, and Mycoplasma hominis from $22 \%$. Chlamydiae and ureaplasmas were isolated less frequently from men with a recent history of NGU. Minocycline was given to 94 patients, and after treatment chlamydiae were isolated from only one of 40 initially chlamydia-positive patients and ureaplasmas from only five of 57 initially ureaplasma-positive patients. Although most patients responded clinically, failure and partial recovery rather than complete recovery were observed more often among those who were infected with ureaplasmas. Rifampicin was given to 123 patients, after which chlamydiae were isolated from only one of 53 initially chlamydia-positive men whereas ureaplasmas, insensitive to the antibiotic in vitro, were isolated from 55 of 68 men who had initially positive results. Patients infected with ureaplasmas failed to respond to rifampicin treatment significantly more often than those who were not infected. This was also observed when only patients who had never had NGU or who had not had a recent episode were considered. Furthermore, $24(44 \%)$ of the 55 men whose ureaplasmas persisted failed to recover whereas only one $(7.7 \%)$ of 13 men whose ureaplasmas disappeared did not respond to treatment. These results suggested that ureaplasmas were a cause of urethritis in some of the men (an estimated $10 \%$ at least). In addition, Reiter's disease developed in two men treated with rifampicin from whom only ureaplasmas had been isolated initially. $M$. hominis did not seem to have an important pathogenic role in NGU and there was evidence that ureaplasmas were an unlikely cause of urethritis in some men since the organisms persisted despite complete clinical recovery.

\section{Introduction}

There is now considerable evidence to implicate Chlamydia trachomatis as one of the causes of nongonococcal urethritis (NGU) (Bowie et al., 1977), although there is still dispute about the way in which chlamydiae cause disease (Richmond and Clarke, 1977). There have been numerous attempts to associate ureaplasmas with NGU and these studies have been discussed recently (Taylor-

Address for reprints: Dr D. Taylor-Robinson, MRC Clinical Research Centre, Watford Road, Harrow, Middlesex HA1 3UJ Received for publication 17 March 1978
Robinson, 1977). Ureaplasmas were previously termed T-strain mycoplasmas, and those of human origin have been ascribed to a new genus and species, Ureaplasma urealyticum (Shepard et al., 1974). The results of a placebo-controlled trial of tetracycline in the treatment of NGU (Prentice et al., 1976), human inoculation of ureaplasmas (TaylorRobinson et al., 1977), and the use of differential antibiotics (Bowie et al., 1976) have provided the most compelling evidence for their involvement in some cases of NGU. In the latter study, urethritis persisted in patients treated with aminocyclitols, which eradicated ureaplasmas but not chlamydiae, and in those treated with sulphafurazole, which 
eliminated chlamydiae but not ureaplasmas. The results supported the importance of both chlamydiae and ureaplasmas in the aetiology of NGU.

In the present study of patients with NGU the effect of treatment with a tetracycline (minocycline) was compared with that of rifampicin. Minocycline inhibits the multiplication of both groups of microorganisms whereas rifampicin inhibits only chlamydiae. Rifampicin has been successfully used in the form of ointment to treat hyperendemic trachoma (Dawson et al., 1975) and paratrachoma (Darougar et al., 1977). If ureaplasmas were responsible for causing urethritis in some patients, we expected that treatment with rifampicin would be less effective than minocycline and that failure to respond would occur mainly in those patients who were infected with ureaplasmas.

\section{Material and methods}

\section{PATIENTS}

Patients attending the special clinic at the Central Middlesex Hospital who complained of urethral discharge were examined. Urethral discharge was Gram-stained and if $\mathbf{1 5}$ or more polymorphonuclear (PMN) leucocytes were present in one microscope field ( $\times 800-1000$ magnification) and gonococci, yeasts, and trichomonads were not seen, the patient was admitted to the trial. Those patients who had received antibiotics during the preceding six weeks or who had passed urine within the previous four hours were excluded.

\section{ANTIBIOTICS}

Rifampicin (Rifadin, Lepetit) is an anti-tuberculous drug. A dose of $600 \mathrm{mg}$ in two tablets was prescribed to be taken 30 minutes before breakfast for six days, giving a total dose of $3 \cdot 6 \mathrm{~g}$.

Minocycline (Minocin, Lederle) is a long-acting tetracycline and therapeutic blood levels of approximately $2 \mu \mathrm{g} / \mathrm{ml}$ are maintained by 12 -hourly oral administration. A loading dose of $200 \mathrm{mg}$ was followed by $100 \mathrm{mg}$ (one tablet) twice a day after meals for six days, giving a total dose of $1 \cdot 3 \mathrm{~g}$.

\section{EXPERIMENTAL DESIGN}

The proposed trial was approved by ethical committees at the Central Middlesex Hospital and the Clinical Research Centre. At the first visit patients were informed that a new treatment was being examined and that it was essential for them to be seen twice more; they were asked to abstain from alcohol and from sexual activity until their dismissal from the clinic. Any patient who admitted to sexual intercourse before that time was withdrawn from the trial. After urethral specimens had been taken to culture for gonococci, mycoplasmas, and chlamydiae, rifampicin tablets or minocycline tablets (which had a similar appearance) were given to the patients on an approximately alternate basis. This was carried out by a staff nurse-in-charge, who kept a record of the treatment which was not disclosed to either the clinician or the microbiologist until after the end of the trial, when all specimens had been tested microbiologically.

The patients returned after seven to 10 days, having completed the six-day course of the antibiotic. Specimens were again taken for culture of mycoplasmas and chlamydiae. If there was a complaint of persistent discharge or a Gramstained smear (which was done in all cases) confirmed the presence of any PMN leucocytes, or both, a six-day course of minocycline was instituted.

The third visit was arranged 14 to 21 days after the start of the treatment, when specimens were again taken for culture. When signs and symptoms subsided the patient was discharged from the clinic.

In the text and tables the following terms are used, which are defined thus: complete recovery means no discharge or complaints and no PMN leucocytes in a Gram-stained urethral smear; partial recovery-no discharge but presence of PMN leucocytes in a smear or greatly reduced discharge; failure - as seen originally; and relapseoccurrence of discharge and PMN leucocytes after complete recovery.

\section{COLLECTION OF SPECIMENS AND}

ISOLATION OF MICRO-ORGANISMS

At the patient's first visit a swab was used to inoculate urethral discharge on to GC selective agar medium (Oxoid). The plates were incubated at $36^{\circ} \mathrm{C}$ in $2 \% \mathrm{CO}_{2}$ in air for 48 hours and examined for the presence of Gram-negative, oxidase-positive diplococci.

At each of the three visits specimens were collected for mycoplasmal and chlamydial culture. A sterile cottonwool-tipped ENT swab was inserted about $2 \mathrm{~cm}$ into the meatus and expressed into $1.8 \mathrm{ml}$ of mycoplasma liquid transport medium. After a maximum of three hours samples were stored at $-70^{\circ} \mathrm{C}$ until tested. They were titrated in urea-containing medium for the detection of ureaplasmas and in arginine-containing medium for Mycoplasma hominis (Taylor-Robinson et al., 1968). The presence of micro-organisms was confirmed by subculture in liquid media, and $M$. hominis was identified by the use of specific antiserum in the disc growth inhibition test. All samples were stored again at $-70^{\circ} \mathrm{C}$.

A specimen for chlamydial culture was always taken second by passing a similar swab $2-3 \mathrm{~cm}$ 
into the urethra. It was expressed into sucrosephosphate transport medium and stored immediately in liquid nitrogen until inoculated into McCoy cell cultures (Darougar et al., 1971). In all cases the cells were treated three days before inoculation with 4500 rads of $\gamma$-irradiation with a cobalt 60 source.

\section{ANTIBIOTIC SENSITIVITY TESTS}

The sensitivity of ureaplasmas to minocycline, erythromycin, and rifampicin was tested by a micro-technique (Taylor-Robinson, 1967), in which each well in the micro-plate contained between $10^{3}$ and $10^{4}$ colour-changing units of the microorganism. The inhibitory antibiotic concentration was that dilution at which there was complete inhibition of colour change after incubation at $36^{\circ} \mathrm{C}$ for 18 hours.

Yates's $\chi^{2}$ test was used for statistical comparisons.

\section{Results}

MICRO-ORGANISMS INITIALLY ISOLATED Of 256 patients seen initially, 39 were excluded because they either had positive culture results for $N$. gonorrhoeae or were not followed up successfully. Thus, there were 217 patients in the trial.

\section{Overall isolation}

As shown in Table 1 chlamydiae were isolated from $93(43 \%)$ men, ureaplasmas from $128(59 \%)$, and $M$. hominis from $47(21 \cdot 6 \%)$. None of these microorganisms was isolated from $50(23 \%)$ patients.

\section{Isolation related to previous episodes of $N G U$}

Of the 217 patients in the trial, 123 claimed that this was their first episode of urethritis while the remainder had had one or more previous attacks. Chlamydiae were isolated from $44 \%$ of patients having a first episode, from 24 (48\%) of 50 who had had one or more distant attacks-that is, not within the preceding six months-and from $15(34 \%)$ of 44 of those who had experienced an attack within the previous six months. The latter isolation rate, however, was not significantly different from the preceding two $\left(\chi_{2}{ }^{2}=1.98, \mathrm{P} \approx 0.35\right)$. On the other hand, ureaplasmas were isolated more frequently both from patients without a previous history of NGU (62\%) and from those who had had one or more distant attacks (64\%) than from those with a recent history $(43 \%)$, a difference which is significant $\left(\chi_{1}^{2}=4.91, P \approx 0.025\right)$. However, $M$. hominis was isolated with similar frequency from each of the three groups of patients $(23 \%, 22 \%$, and $18 \%)$. In view of the above findings it is not surprising that the proportion of patients from whom microorganisms could not be isolated was significantly greater among those experiencing a recent new attack of NGU (43\%) than among those having their first episode $(20 \%)$ or who had experienced a distant attack $(20 \%)\left(\chi_{2}^{2}=9 \cdot 89, p \approx 0.006\right)$.

\section{CLINICAL RESPONSE TO TREATMENT}

Minocycline was given to 94 patients and rifampicin to 123 patients (Table 2). Treatment with minocycline was significantly more effective; $68 \%$ of patients given this antibiotic recovered completely whereas only $37.4 \%$ of patients given rifampicin did so $\left(\chi_{2}{ }^{2}=24.07, P<0.001\right)$. The proportion of patients who relapsed was about the same whether they were treated with minocycline or rifampicin.

\section{RESPONSE TO TREATMENT WITH MINOCYCLINE IN RELATION TO MICRO-ORGANISMS \\ INITIALLY ISOLATED}

\section{Microbiological response}

After treatment with minocycline (Table 3), chlamydiae were isolated from only one of 40 initially chlamydia-positive patients, ureaplasmas from five of 57 initially ureaplasma-positive patients, and $M$. hominis from three of 18 persons who had been infected by this mycoplasma.

\section{Clinical response}

The one patient who still harboured chlamydiae after minocycline treatment and had failed to

Table 1 Micro-organisms initially isolated from 217 patients with NGU

\begin{tabular}{|c|c|c|c|c|}
\hline \multirow[b]{2}{*}{ Positive isolation findings } & \multirow[b]{2}{*}{ No. of patients } & \multicolumn{3}{|c|}{ No. of positive findings for each micro-organism } \\
\hline & & Chlamydiae & M. hominis & Ureaplasmas \\
\hline $\begin{array}{l}\text { Chlamydiae alone } \\
\text { Chlamydiae and } M \text {. hominis } \\
\text { Chlamydiae, } M \text {. hominis, and ureaplasmas } \\
\text { Chlamydiae and ureaplasmas } \\
\text { Ureaplasmas alone } \\
\text { Ureaplasmas and } M . \text { hominis } \\
M \text {. hominis alone } \\
\text { Total }\end{array}$ & $\begin{array}{r}34 \\
1 \\
18 \\
40 \\
46 \\
24 \\
4 \\
167(77 \%)\end{array}$ & $\begin{array}{r}34 \\
1 \\
18 \\
40\end{array}$ & $\begin{array}{l}24 \\
4 \\
47(21 \cdot 6 \%)\end{array}$ & $\begin{array}{c}18 \\
40 \\
46 \\
24 \\
128(59 \%)\end{array}$ \\
\hline
\end{tabular}


Table 2 Effect of minocycline or rifampicin on 217 patients with NGU

\begin{tabular}{|c|c|c|c|c|}
\hline \multirow[b]{3}{*}{ Clinical response } & \multicolumn{4}{|c|}{ Treatment } \\
\hline & \multicolumn{2}{|c|}{ Minocycline } & \multicolumn{2}{|c|}{ Rifampicin } \\
\hline & No. & $\%$ & No. & $\%$ \\
\hline $\begin{array}{l}\text { Completely recovered } \\
\text { Partially recovered } \\
\text { Failure (persistent discharge or PMN or both) } \\
\text { Total } \\
\text { Relapsed }\end{array}$ & $\begin{array}{r}64 \\
24 \\
6 \\
94 \\
8\end{array}$ & $\begin{array}{c}68 \\
25 \cdot 5 \\
6 \cdot 5 \\
100 \\
8 \cdot 5\end{array}$ & $\begin{array}{r}46 \\
44 \\
33 \\
123 \\
11\end{array}$ & $\begin{array}{c}37 \cdot 4 \\
35 \cdot 8 \\
26 \cdot 8 \\
100 \\
9\end{array}$ \\
\hline
\end{tabular}

Table 3 Persistence of chlamydiae, ureaplasmas, and $\mathrm{M}$. hominis after treatment

\begin{tabular}{|c|c|c|c|c|c|c|}
\hline \multirow[b]{3}{*}{ Initial isolation* } & \multicolumn{6}{|c|}{ Proportion of patients $\dagger$ infected by micro-organisms following treatment } \\
\hline & \multicolumn{3}{|l|}{ Minocycline } & \multicolumn{3}{|l|}{ Rifampicin } \\
\hline & Chlamydiae & Ureaplasmas & M. hominis & Chlamydiae & Ureaplasmas & M. hominis \\
\hline $\begin{array}{l}\text { Chlamydia-positive ureaplasma- } \\
\text { positive }(C+U+) \\
\text { Chlamydia-negative, ureaplasma- }\end{array}$ & $0 / 28$ & $2 / 28$ & $0 / 6$ & $0 / 30$ & $23 / 30$ & $9 / 10$ \\
\hline $\begin{array}{l}\text { positive }(\mathrm{C}-\mathrm{U}+) \\
\text { Chlamydia-positive, ureaplasma- }\end{array}$ & & $3 / 29$ & $2 / 9$ & & $32 / 38$ & $10 / 14$ \\
\hline $\begin{array}{l}\text { negative (C+U-) } \\
M . \text { hominis only }\end{array}$ & $1 / 12$ & & $1 / 3$ & $1 / 23$ & & $\begin{array}{l}1 / 1 \\
0 / 1\end{array}$ \\
\hline Total & $1 / 40$ & $5 / 57$ & $3 / 18$ & $1 / 53$ & $55 / 68$ & $20 / 26$ \\
\hline
\end{tabular}

*Including $M$. hominis

$\dagger$ The microbiological status of a few patients after treatment was not assessed. The total number of patients in each category is shown in Table 4

respond clinically did so with the disappearance of the organisms after erythromycin was given. Of the five patients who were still infected by ureaplasmas after treatment, one had completely recovered, two had partially recovered, one had failed treatment, and another had relapsed.

The clinical response is further analysed according to the micro-organisms - chlamydiae (C) or ureaplasmas (U)-initially isolated; the patients are placed in four groups according to the positive $(+)$ or negative (-) findings for each organism; $\mathrm{C}+\mathrm{U}+$, $\mathbf{C}-\mathbf{U}+, \mathbf{C}+\mathbf{U}-$, and $\mathbf{C}-\mathbf{U}-$, as shown in Tables 3 and 4 . Few patients failed to respond to treatment and the proportion who did fail was about the same in each group. Because there were so few failures these patients were grouped with those who had a partial recovery for statistical purposes. Although most patients responded, failure and partial recovery rather than complete recovery tended to occur more often among those who were infected with ureaplasmas, the difference being most obvious, but not quite significant, when the $\mathrm{C}+\mathrm{U}+$ and $\mathrm{C}-\mathrm{U}+$ groups were compared with the $\mathrm{C}+\mathrm{U}-$ group $\left(\chi_{1}{ }^{2}=3 \cdot 18, \quad P \approx 0.07\right)$. Other comparisons did not approach a significant value.

The poorer clinical response to minocycline of patients who possessed ureaplasmas appeared to be a feature of those who had experienced a previous recent episode of NGU (Table 5), although the number of patients was small and unsuitable for statistical analysis.
RESPONSE TO TREATMENT WITH RIFAMPICIN IN RELATION TO MICRO-ORGANISMS INITIALLY ISOLATED

\section{Microbiological response}

After treatment with rifampicin (Table 3) chlamydiae were isolated from only one of 53 initially chlamydiapositive patients. In contrast, ureaplasmas were isolated from 55 of 68 initially ureaplasma-positive patients, and $M$. hominis from 20 of 26 patients originally infected by this mycoplasma.

\section{Clinical response in relation to chlamydiae}

Surprisingly, the one patient from whom chlamydiae were not eradicated had a successful clinical response. In fact, few patients from whom only chlamydiae had been isolated originally failed to respond to treatment (Table 4). Despite failure to isolate the organisms following rifampicin treatment, however, the proportion of patients who completely recovered was smaller than after minocycline treatment.

\section{Clinical response in relation to ureaplasmas}

In 13 of the 68 patients ureaplasmas disappeared after treatment. Twelve of these 13 patients completely or partially recovered and only one $(7.7 \%)$ failed to do so, whereas of the 55 patients whose ureaplasmas persisted 31 completely or partially recovered and $24(43.6 \%)$ failed to recover.

Further analysis of the results (Table 4) shows 
Table 4 Clinical response to treatment in relation to initial microbiological status

\begin{tabular}{|c|c|c|c|c|c|}
\hline \multirow[b]{2}{*}{ Treatment and clinical response } & \multicolumn{4}{|c|}{ No. of patients with following initial isolation findings } & \multirow[b]{2}{*}{ Total } \\
\hline & $C+U+$ & $C-U+$ & $C+U-$ & $C-U-$ & \\
\hline With minocycline & 28 & 29 & 12 & 25 & 94 \\
\hline Complete recovery & 17 & 17 & 11 & 18 & 64 \\
\hline Partial recovery & $11(39 \cdot 3 \%)$ & $10(34 \cdot 5 \%)$ & 0 & 4 & 24 \\
\hline Failed & 0 & 2 & 1 & 3 & 6 \\
\hline Relapsed & 1 & 4 & 2 & 1 & 8 \\
\hline With rifampicin & 30 & 41 & 23 & 29 & 123 \\
\hline Complete recovery & 9 & 16 & 10 & 11 & 46 \\
\hline Partial recovery & 9 & 12 & 11 & 12 & 44 \\
\hline Failed & $12(40 \%)$ & $13(31 \cdot 7 \%)$ & $2(8 \cdot 7 \%)$ & $6(20 \cdot 7 \%)$ & 33 \\
\hline Relapsed & 4 & 4 & 1 & 2 & 11 \\
\hline
\end{tabular}

Table 5 Clinical response to treatment in relation to previous disease

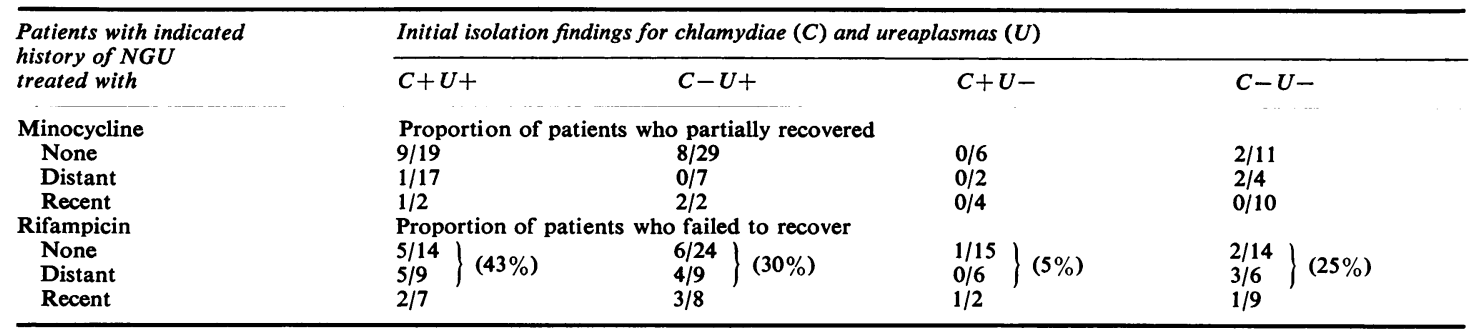

that the patients who failed to respond to rifampicin were most frequently those who were originally infected with ureaplasmas. Thus, complete and partial recovery occurred in 46 patients in the combined $\mathrm{C}+\mathrm{U}+$ and $\mathrm{C}-\mathrm{U}+$ groups and in 44 in the combined $\mathrm{C}+\mathrm{U}-$ and $\mathrm{C}-\mathrm{U}-$ groups. Failure to respond, however, occurred in 25 in the $\mathbf{C}+\mathbf{U}+$ and $\mathbf{C}-\mathbf{U}+$ groups compared with only eight in the $\mathrm{C}+\mathrm{U}-$ and $\mathrm{C}-\mathrm{U}-$ groups $\left(\chi_{1}{ }^{2}=5 \cdot 04\right.$,

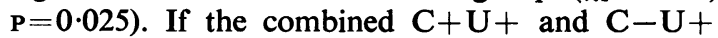
groups are compared with the $\mathrm{C}+\mathrm{U}-$ group only (two failures and 21 recoveries in the latter group) the larger number of failures in the ureaplasmapositive groups is again significant $\left(\chi_{1}{ }^{2}=4 \cdot 74\right.$, $\mathrm{P} \approx 0.03$ ).

The failure of initially ureaplasma-positive patients to respond to rifampicin was seen about as frequently in those who had had a recent episode of NGU as in the remainder of the patients (Table 5). Placing these latter patients, from whom microorganisms were isolated most frequently, into groups as previously-that is, $\mathbf{C}+\mathrm{U}+, \mathbf{C}-\mathbf{U}+$, $\mathrm{C}+\mathrm{U}-, \mathbf{C}-\mathrm{U}-$-showed that treatment failures occurred more often in the groups containing ureaplasmas (Table 5) $\left(\chi_{1}{ }^{2}=4 \cdot 34, \mathrm{P} \approx 0.04\right)$, as noted previously for the patients as a whole (Table 4).

A closer examination of the data on the 31 patients who were initially infected by ureaplasmas and who completely or partially recovered showed that the organisms were unlikely to be the cause of disease in at least nine of them. The latter patients completely recovered and remained well for up to three weeks, even though at the time of the second and third visits ureaplasmas were isolated in numbers similar to those observed initially.

\section{Clinical response in relation to $\mathrm{M}$. hominis}

As shown in Table $1, M$. hominis was isolated predominantly from patients who were infected with ureaplasmas. It was possible that the failure of ureaplasma-positive patients to respond to rifampicin was due to their concurrent infection with $M$. hominis. To assess this, the clinical response of patients infected with $M$. hominis was compared with the response of those who were not infected (Table 6). The proportion of patients who failed to respond to treatment was about the same in the $\mathrm{U}+M$. hominis + group as in the ureaplasmaonly group. In contrast, the proportion who failed to respond in the $\mathrm{U}+\mathrm{C}+M$. hominis + group was greater than in the $\mathbf{U}+\mathbf{C}+$ only group. Further analysis, however, indicated that failure to respond in the former group might be attributable to $M$. hominis in only one of the five patients.

Relationship of disease severity to micro-organisms isolated and to clinical outcome

To determine whether differences in the severity of disease were associated with particular microorganisms the symptoms and signs were correlated 
Table 6 Clinical response to rifampicin of patients who were infected or not infected by M. hominis

\begin{tabular}{|c|c|c|c|c|c|c|}
\hline \multirow[b]{2}{*}{ Group treated } & \multirow[b]{2}{*}{ No. of patients } & \multirow[b]{2}{*}{ Complete recovery } & \multirow[b]{2}{*}{ Partial recovery } & \multicolumn{2}{|c|}{ Failed } & \multirow[b]{2}{*}{ Relapse } \\
\hline & & & & No. & $\%$ & \\
\hline $\begin{array}{l}\mathrm{U}+M \text {. hominis }+ \\
\mathrm{Ureaplasmas} \text { only } \\
\mathrm{U}+\mathrm{C}+M \text {. hominis }+ \\
\mathrm{U}+\mathrm{C}+\text { only }\end{array}$ & $\begin{array}{l}15 \\
26 \\
10 \\
20\end{array}$ & $\begin{array}{r}5 \\
12 \\
3 \\
6\end{array}$ & $\begin{array}{l}5 \\
7 \\
2 \\
9\end{array}$ & $\begin{array}{l}5 \\
7 \\
5 \\
5\end{array}$ & $\begin{array}{l}33 \\
27 \\
50 \\
25\end{array}$ & $\begin{array}{l}3 \\
1 \\
1 \\
3\end{array}$ \\
\hline
\end{tabular}

with the organisms initially isolated in two groups of patients, namely those from whom chlamydiae but not ureaplasmas were isolated and those from whom ureaplasmas but not chlamydiae were isolated. The amount of discharge was based on a ,,++++++ score denoting minimal, moderate, and severe, and the total score for all patients within a group was divided by the number of patients to obtain an average discharge score. The number of polymorphonuclear (PMN) leucocytes observed on a Gram-stained smear was likewise summarised for all patients and divided by the number of patients to obtain an average PMN leucocyte score. For patients who were chlamydiapositive only, the average discharge score was 1.94 and the average PMN leucocyte score 19.7. For patients who were ureaplasma-positive only, the average discharge score was $2 \cdot 16$ and the average PMN leucocyte score $20 \cdot 3$. There was, therefore, no evidence that the presence of one or other of these micro-organisms was associated with more severe disease.

Data were analysed on the group of patients in which most treatment failures occurred-namely those patients treated with rifampicin who were initially chlamydia-negative but ureaplasma-positive-to determine whether severe disease resulted in failure to recover clinically. There was no evidence for this because the average discharge score was 2.0 and the average PMN leucocyte score was $19 \cdot 2$ for those who failed to respond, and 2.0 and 18.4 respectively for those who recovered.

\section{Antibiotic sensitivity tests}

Chlamydiae persisted in one patient after minocycline treatment and in one patient after rifampicin treatment (Table 3), but unfortunately the organisms were not available for antibiotic sensitivity tests. Ureaplasmas persisted in five patients after minocycline treatment (Table 3) but were sensitive to $0.01 \mu \mathrm{g} / \mathrm{ml}$ of the antibiotic. Ureaplasmas were not recovered from 13 patients following rifampicin treatment, but apparently this was not due to the effect of the antibiotic because the organisms initially isolated from these patients were resistant to $80 \mu \mathrm{g} / \mathrm{ml}$ of rifampicin.

\section{Development of Reiter's disease}

Ureaplasmas but not chlamydiae were isolated from the urethral discharge of two patients. Both patients were treated with rifampicin and the ureaplasmas and discharge persisted but these had disappeared two weeks after the initial visit to the clinic following a course of minocycline. The first signs of Reiter's disease were observed one week after the initial visit in the case of the first patient and two weeks after in the case of the second.

\section{Discussion}

In this study we isolated chlamydiae and $M$. hominis more frequently than we had done previously (Prentice et al., 1976), and the rate of isolation of both chlamydiae and ureaplasmas was comparable with that observed by other workers (Wentworth, 1977; Taylor-Robinson, 1976). Thus, the recovery of micro-organisms was sufficiently satisfactory to enable us to correlate the microbiological results with the outcome of treatment. As noted by others (Alani et al., 1977) and previously by ourselves (Prentice et al., 1976), a past history of NGU was associated with a lower isolation rate. This occurred, however, only if there had been a previous episode within the six-month period immediately preceding the current infection.

Bowie et al. (1976), in part of their study, used aminocyclitols which eradicated ureaplasmas but not chlamydiae. Since there is now considerable evidence, as mentioned previously, that chlamydiae are pathogens in the male genital tract, we considered that it would be unwise to withhold treatment from chlamydia-positive patients. We, therefore, did not use a drug which was ineffective against chlamydiae but confined the study to a comparison of rifampicin, which inhibits chlamydiae but not ureaplasmas, with minocycline, which inhibits the multiplication of both micro-organisms. Chlamydiae could not be recovered from the urethra following rifampicin treatment, and indeed there was no evidence that rifampicin-resistant strains emerged as the findings of other workers (Keshishyan et al., 1973) suggested might happen. Despite apparent 
eradication rifampicin was less effective in treating chlamydia-positive patients than minocycline, which may have been due to the greater bactericidal activity of the latter drug (Treharne et al., 1977). It was interesting to note that treatment with minocycline was not so successful clinically when ureaplasmas, with or without chlamydiae, were present. This in itself may be evidence for a differential antibiotic effect, the antibiotic destroying chlamydiae but having a more static than cidal effect on ureaplasmas. Failure to respond to therapy on account of the presence of minocycline-resistant ureaplasmas, however, was not encountered, although such strains have been found previously (Evans and Taylor-Robinson, 1978).

Most patients who failed to respond to treatment had been given rifampicin, and failure occurred significantly more frequently in those patients who were infected with ureaplasmas than in those who were not. This observation is in keeping with that of Bowie et al. (1976), who found that sulphafurazolewhich eliminated chlamydiae but not ureaplasmas-was less successful when patients were infected by the latter micro-organisms than when they were not. The results of both studies suggest that ureaplasmas are a cause of some cases of NGU, although, as indicated below, there are problems in evaluating the data.

The group of 29 patients who were treated with rifampicin and from whom chlamydiae and ureaplasmas were not isolated initially $(\mathrm{C}-\mathrm{U}-)$ is virtually a micro-organism-negative group comprising only one $M$. hominis-positive patient. Whether the $\mathrm{C}-\mathrm{U}-$ group of patients is one with which the other groups may be validly compared is an aspect which influences the interpretation of the results. Thus, while a greater proportion of patients who possessed ureaplasmas failed to respond to treatment than those who did not $(\mathrm{C}+\mathrm{U}-$ and $\mathrm{C}-\mathrm{U}-$ groups combined or $\mathrm{C}+\mathrm{U}-$ ), this was not so if the groups possessing ureaplasmas were compared with the $\mathrm{C}-\mathrm{U}-$ group, an aspect not mentioned by Bowie et al. (1976). The question arises of whether the only difference between the $\mathrm{C}-\mathrm{U}+$ group and the $\mathrm{C}-\mathrm{U}-$ group of patients is the absence of ureaplasmas or whether the latter group of patients is infected by different microorganisms entirely and is therefore unacceptable for comparative purposes. It seems rather likely that the $\mathbf{C}-\mathbf{U}-$ group does not comprise undetectable chlamydiae-preliminary serological studies providing further evidence for their absence (B. Thomas, personal communication)-although the existence of a few, as yet, undetectable ureaplasmas has not been eliminated. The available evidence suggests, therefore, that the group is somewhat different from the others and should not be used for comparative purposes. This belief is reinforced by the fact that patients in the $\mathrm{C}+\mathrm{U}-$ group did not respond significantly better to rifampicin than those in the $\mathrm{C}-\mathrm{U}-$ group, an unlikely result if the only difference between the patients in the two groups was the possession of chlamydiae by the former. The fact that a substantial proportion of the patients within the $\mathrm{C}-\mathrm{U}-$ group responded to antibiotics suggests that they were infected with antibiotic-sensitive organisms, and there is clearly a need to establish what these were.

In recent times, $M$. hominis has not been seriously considered as a potential pathogen in the male urogenital tract. Nevertheless, this mycoplasma cannot be ignored in the present study because it is also insensitive to rifampicin, so that treatment failures attributed to ureaplasmas could be due to $M$. hominis in those cases where it co-existed. The results suggest the $M$. hominis is, at the most, rarely pathogenic. The study, however, was not designed to evaluate the role of this mycoplasma; this might best be done by treating the $\mathrm{C}-\mathrm{U}+\mathrm{M}$. hominis + group of patients with lincomycin, which inhibits $M$. hominis but not ureaplasmas, and with erythromycin, which has the reverse effect.

As expected, ureaplasmas which initially infected patients usually persisted after rifampicin treatment. In some cases, however, the organisms could not be reisolated and their disappearance was not due to their sensitivity to the antibiotic. This is the first evidence of spontaneous clearance of ureaplasmas from adult male patients and contrasts with the results of previous studies where persistence for at least a year was noted in the absence of antibiotic therapy (Holmes et al., 1974; MacLeod et al., 1976). Patients in whom ureaplasmas disappeared recovered more frequently than those in whom the organisms persisted. This observation might be used as evidence for a causative role of ureaplasmas but it is not possible to know whether the patients improved because the organisms disappeared or whether the organisms were not recoverable because the disease subsided spontaneously, isolation being less easily achieved in the absence of discharge. The latter possibility seems less likely, however, because there were several examples of patients who made a complete clinical recovery and yet ureaplasmas persisted in numbers similar to those observed initially. In such cases it seems unlikely that the ureaplasmas were responsible for the disease. What proportion of patients might have urethritis accountable for by ureaplasmal infection is therefore an obvious question. In the $\mathrm{C}-\mathrm{U}+$ group treated with rifampicin, 13 of 41 patients failed to respond. Thus, if all 70 patients in the $\mathrm{C}-\mathrm{U}+$ group - that 
is, those treated with rifampicin and minocyclinehad in fact been treated with rifampicin alone, it can be calculated that 22 of them would have failed to respond as a result of possessing ureaplasmas. It would seem reasonable to consider, therefore, that a minimum of $10 \%$ of patients (that is, 22/217) had a urethritis due to ureaplasmas. In patients infected by chlamydiae the ureaplasmas may, of course, contribute to the disease. It is interesting that in both of the patients who developed Reiter's disease ureaplasmas but not chlamydiae were isolated from the urethral discharge of each of them. Whether inadequate treatment with rifampicin contributed to the development of the disease is a moot point. The intriguing question of whether ureaplasmas play a significant role in Reiter's disease can only be answered by undertaking a planned prospective study in which patients with NGU are assessed microbiologically before they develop Reiter's disease (Taylor-Robinson, 1979).

We thank the staff of the clinic at the Central Middlesex Hospital for their help in this study, Mr R. T. Evans and Mrs Mary Osborn for some technical assistance, and Mr D. Altman for help with the statistical analyses.

\section{References}

Alani, M. D., Darougar, S., Burns, D. C. MacD., Thin, R. N., and Dunn, H. (1977). Isolation of Chlamydia trachomatis from the male urethra. British Journal of Venereal Diseases, 53, 88-92.

Bowie, W. R., Alexander, E. R., Floyd, J. F., Holmes, J., Miller, Y., and Holmes. K. K. (1976). Differential response of chlamydial and ureaplasma-associated urethritis to sulphafurazole (sulfisoxazole) and aminocyclitols. Lancet, 2, 1276-1278.

Bowie, W. R., Wang, S.-P., Alexander, E. R., and Holmes, K. K. (1977). Etiology of nongonococcal urethritis. In Nongonococcal Urethritis and Related Infections, pp. 19-29. Edited by D. Hobson and K. K. Holmes. American Society for Microbiology: Washington, D.C.

Darougar, S., Kinnison, J. R., and Jones, B. R. (1971). Chlamydial isolates from the rectum in association with chlamydial infection of the eye or genital tract. I. Laboratory aspects. In Trachoma and Related Disorders, pp. 501-506. Edited by R. L. Nichols. Excerpta Medica: Amsterdam.

Darougar, S., Viswalingam, M., Treharne, J. D., Kinnison, J. R., and Jones, B. R. (1977). Treatment of TRIC infection of the eye with rifampicin or chloramphenicol. British Journal of Ophthalmology, 61, 255-259.
Dawson, C. R., Hoshiwara, I., Daghfous, T., Messadi, M., Vastine, D. W., and Schachter, J. (1975). Topical tetracycline and rifampicin therapy of endemic trachoma in Tunisia. American Journal of Ophthalmology, 79, 803-811.

Evans, R. T., and Taylor-Robinson, D. (1978). The incidence of tetracycline-resistant strains of Ureaplasma urealyticum. Journal of Antimicrobial Chemotherapy, 4, 57-63.

Holmes, M. J., Furr, P. M., and Taylor-Robinson, D. (1974). The persistence of ureaplasmas in the urogenital tract of men in the Antarctic. Journal of Hygiene, 72, 355-363.

Keshishyan, H., Hanna, L., and Jawetz, E. (1973). Emergence of rifampicin-resistance in Chlamydia trachomatis. Nature, 244, 173-174.

MacLeod, A. D., Furr, P. M., and Taylor-Robinson, D. (1976). Prolonged eradication of urogenital mycoplasmas after administration of tetracycline to men in the Antarctic. British Journal of Venereal Diseases, 52, 337-340.

Prentice, M. J., Taylor-Robinson, D., and Csonka, G. W. (1976). Non-specific urethritis. A placebo-controlled trial of minocycline in conjunction with laboratory investigations. British Journal of Venereal Diseases, 52, 269-275.

Richmond, S. J., and Clarke, S. K. R. (1977). Problems in assigning a causative role to chlamydiae isolated in nongonococcal urethritis. In Nongonococcal Urethritis and Related Infections, pp. 43-46. Edited by D. Hobson and K. K. Holmes. American Society for Microbiology: Washington, D.C.

Shepard, M. C., Lunceford, C. D., Ford, D. K., Purcell, R. H., Taylor-Robinson, D., Razin, S., and Black, F. T. (1974). Ureaplasma urealyticum gen. nov., sp. nov.: proposed nomenclature for the human T (T-strain) mycoplasmas. International Journal of Systematic Bacteriology, 24, 160-171.

Taylor-Robinson, D. (1967). Mycoplasmas of various hosts and thei antibiotic sensitivities. Postgraduate Medical Journal, 43, 100-104.

Taylor-Robinson, D. (1976). Mycoplasmas in the male urogenital tract. In Scientific Foundations of Urology Volume 1, pp. 223-227. Edited by D. I. Williams and G. D. Chisholm. Heinemann London.

Taylor-Robinson, D. (1977). Possible role of ureaplasmas in nongonococcal urethritis. In Nongonococcal Urethritis and Related Infections, pp. 30-37. Edited by D. Hobson and K. K. Holmes. American Society for Microbiology: Washington, D.C.

Taylor-Robinson, D. (1979). The biology and immunology of chlamydiae in relation to reactive arthritis. In Current Research in Rheumatoid Arthritis and Allied Diseases. Edited by D. C. Dumonde and R. N. Maini. Medical \& Technical Publications Press Ltd.: Lancaster. In press.

Taylor-Robinson, D., Csonka, G. W., and Prentice, M. J. (1977). Human intra-urethral inoculation of ureaplasmas. Quarterly Journal of Medicine, New Series, 46, 309-326.

Taylor-Robinson, D., Williams, M. H., and Haig, D. A. (1968). The isolation and comparative biological and physical characteristics of T-mycoplasmas of cattle. Journal of General Microbiology, 54, $33-46$.

Treharne, J. D., Day, J., Yeo, C. K., Jones, B. R., and Squires, S. (1977). Susceptibility of chlamydiae to chemotherapeutic agents. In Nongonococcal Urethritis and Related Infections, pp. 214-222. Edited by D. Hobson and K. K. Holmes. American Society for Microbiology: Washington, D.C.

Wentworth, B. B. (1977). Sensitivity of cell culture for isolation of Chlamydia trachomatis from genital sources. In Nongonococcal Urethritis and Related Infections, pp. 299-303. Edited by D. Hobson and K. K. Holmes. American Society for Microbiology: Washington, D.C. 